\title{
Long-Term Fertilization Alters the Chemical Composition of Dissolved Organic Carbon via Regulating Soil Physicochemical Factors
}

\section{Yang Zhang}

Chinese Academy of Agricultural Sciences

Shengzhe $E$

Gansu Academy of Agricultural Sciences

\section{Yanan Wang}

Chinese Academy of Agricultural Sciences

Nan Zhang

Chinese Academy of Agricultural Sciences

\section{Cuixia Wu}

Chinese Academy of Agricultural Sciences

Xibai Zeng ( $\nabla$ zengxibai@caas.cn )

Institute of Environment and Sustainable Development in Agriculture, Chinese Academy of Agricultural Sciences

\section{Research Article}

Keywords: Carbon chemical structure, Carbon groups turnover, Labile carbon groups, Manure application, Soil nutrient, Spectral analysis, Stable carbon structures

Posted Date: September 13th, 2021

DOI: https://doi.org/10.21203/rs.3.rs-808170/v1

License: (c) (1) This work is licensed under a Creative Commons Attribution 4.0 International License. Read Full License 


\section{Abstract}

Soil dissolved organic carbon (DOC) plays a key role in fundamental biogeochemical processes; however, the influences of different types of fertilization on the chemical composition and properties of DOC molecules in soils are poorly understood. In this study, DOC samples were extracted from gray desert soils treated with five fertilization treatments 1 ) chemical nitrogen, phosphorus and potassium fertilizers; 2) pig and cattle manure; 3) $50 \%$ nitrogen from manure and $50 \%$ nitrogen from chemical fertilizer; 4) total chemical fertilizers and total manure; and 5) no fertilization (control). Data were compared by a combination of Fourier-transform infrared spectroscopy, ${ }^{13} \mathrm{C}$ nuclear magnetic resonance, and statistical analyses. Results showed that manure application increased the aliphatic carbon and decreased the aromatic carbon levels, implying manure application promotes the transformation of labile carbon to stable carbon structures. Redundancy analysis indicated that available nutrients and available forms of magnesium were positively associated with the labile carbon groups, and the available forms of calcium were positively associated with the stable carbon groups. These results demonstrated that the availability of soil nutrients and minerals are influential factors on DOC turnover. Moreover, our results showed that fertilization method had negative direct effects on DOC transformation and positive indirect effects on DOC turnover via soil physicochemical factors, and various forms of mineral ions were the strongest explanatory factors of DOC variation. These findings indicated that soil physicochemical factors play an important role as mediators in the influence of fertilization practices on the chemical composition of DOC and turnover of carbon-containing functional groups in DOC.

\section{Introduction}

Dissolved organic carbon (DOC), a small and labile forms of soil organic carbon, plays an important role in various biogeochemical processes (Taylor and Townsend 2010). Its composition directly provides information on the production or degradation of organic matter (Schmidt et al. 2011). It primarily originates microbial metabolites, plant biomass and organic matter (Malik and Gleixnerm 2013; Roth et al. 2019). Its production and turnover are affected by biotic factors (e.g., microbial diversity and enzyme activity) and abiotic factors (e.g., moisture and temperature). Among all factors, the forms of soil clay minerals appear to be one of most significant factors because they affect the decomposition of soil organic carbon by the physical and chemical protection (Yu et al. 2017). For example, exchangeable mineral ions preferentially bind organic acid molecules that are highly unsaturated or rich in oxygen by ionic or covalent bonds (Yu et al. 2012). The latest information about DOC have shown that various forms of soil mineral ions affect the transformation of DOC by selectively retaining the DOC carbon groups (e.g., carboxylate bound to the surface of calcium carbonate) or by regulating the abundances of microorganisms that affect DOC turnover (Leinemann et al. 2018; Wen et al. 2014).

Soil aggregates influences the DOC composition and turnover by mediating the kinetics processes of soil organic matter (Xu et al. 2021). Mineral-bound organic molecules can be retransformed through the destruction or construction of soil aggregates (Zhao et al. 2020). Aggregate stabilization processes (e.g., cementation and agglomeration) can alter remobilized DOC molecules or retransformation of carbon- 
containing groups by spatial isolation (Xu et al. 2019). Those changes in DOC are accompanied by variations in soil physicochemical properties. Soil physicochemical properties (e.g., soil nutrient availability, $\mathrm{pH}$ and cation exchange capacity) not only influence the molecular properties of DOC (Smebye et al. 2016) but also affect the efficiency of the microbial metabolism in degrading carboncontaining groups (Chen et al. 2017). The microbial community probably assembles new molecules or groups in the consumption and degradation of DOC (Wu et al. 2018).

Besides biotic factors and abiotic factors, the agronomic practices such as tillage (Bongiorno et al. 2019), irrigation (Said-Pullicino et al. 2016) and fertilization (Li et al. 2019) also influence DOC production and turnover. Fertilization is one of the primary factors influencing DOC turnover in agronomic practices. Chemical nitrogen fertilizer application promotes the preferential mineralization of saturated carbon groups (e.g., alkanes) and accumulation of unsaturated carbon (e.g., aromatic groups) in DOC by changing the ratio of carbon to nitrogen $(\mathrm{C} / \mathrm{N})$ in soils (Wang et al. 2020). Meanwhile, a long-term fertilization experiment indicates that aromatic carbon content increases with nitrogen addition ( $\mathrm{Li}$ et al. 2019). The stepwise degradation of cellulose to extended aromatic compounds, an important contributor to DOC production, has shown to be more efficient in nitrogen-fertilized than non-fertilized plots (Yuan et al. 2018).

The current understanding of fertilization on DOC turnover suggests that fertilization directly influence the amount or ratio of labile group and inert group in DOC by the inherent inputs of exogenous matter (Singh et al. 2014), or indirectly impact DOC composition by regulating microbial activity and community (Wang et al. 2015; Zang et al. 2017). However, recent results reveal that DOC composition and turnover may be more susceptible to the influential factors of its surrounding environment (e.g., nutrient availability, aggregate stability and mineral forms) than to fertilization (Li et al. 2019; Wang et al. 2021). Furthermore, one study found that long-term fertilization influences DOC composition mainly via regulating soil aggregate size, not direct effect (Xu et al. 2021).

Gray desert soil, developed from loess parent material, is an important zonal soil in temperate desert areas with rich in the minerals of calcium and magnesium (Wang et al. 2016). The area where it is located has less precipitation and a high rate of DOC production and turnover. The increased mineralization of organic matter caused by the rapid turnover of DOC has become one of the main obstacles to the development of local agriculture and animal husbandry (Wang et al. 2016). The relationships between DOC properties and minerals of calcium or magnesium have been reported (Minick et al. 2017; Zhu et al. 2019), but the underlying mechanisms of how mineral forms of calcium or magnesium act as mediators to regulate the DOC turnover are still largely unknown.

Applying the Fourier transform infrared (FTIR) spectroscopy and ${ }^{13} \mathrm{C}$ nuclear magnetic resonance $\left({ }^{13} \mathrm{C}\right.$ NMR) techniques has allowed us to capture the variation in carbon-containing groups of DOC (Hayes et al. 2017). This provides a more detailed molecular-level understanding of DOC-group turnover. In this study, we conducted a long-term field experiment comparing different fertilization managements and used FTIR spectroscopy and ${ }^{13} \mathrm{C}$-NMR to quantitatively determine how the different fertilization strategies 
affected the composition and chemical properties of DOC. We hypothesized that soil physicochemical properties are the key agents for the DOC turnover driven by fertilization practices. We characterized the chemical composition of DOC and analyzed the implications of fertilization on the turnover of DOC groups and the role of soil physical and chemical properties in the turnover process. We expect that the results will contribute to understanding the DOC turnover and help to predict carbon cycling in agroecosystems.

\section{Materials And Methods}

\subsection{Field experiment and sampling}

The field experiment is located near Hexi Corridor in Gansu Province, Northwest China $\left(37^{\circ} 53 \rrbracket \mathrm{N}, 102^{\circ} 40 \rrbracket\right.$ E, elevation $1540 \mathrm{~m}$; MAP and MAT of $150 \mathrm{~mm}$ and $7.7^{\circ} \mathrm{C}$, respectively). We previously reported a detailed description of field site, treatment, soil sampling and analyses (Zhang et al., 2021). In brief, three soil cores (0-20 cm deep) were collected in March 2019 from plots that were established in 2007 with one of five fertilization strategies (chemical nitrogen, phosphorus and potassium fertilizers [NPK], pig and cattle manure [M], 1/2NPK and 1/2M [1/2MNPK], total NPK and total M [MNPK], and no-fertilization control [CT]). Three soils were composited in one soil sample per plot and $500 \mathrm{~g}$ of the composite sample was taken as the final sample. All soil samples were air-dried and each passed through a 2-mm sieve prior to further analyses and DOC extraction experiments. The methods of measuring and determining the indices of basic soil properties, aggregate stability, calcium forms and magnesium forms are presented in Supplementary Appendix SI.

\subsection{DOC preparation and characterization}

In this study, the water-extractable organic carbon was used to instead of the organic carbon in soil solution. Although the water-extractable organic carbon does not exclusively reflect the in-situ dissolved composition, the water-extractable organic carbon contains almost all the carbon groups in the soil solution and does not affect the characterization of dissolved organic carbon composition (Ding et al. 2020). Therefore, the water-extractable organic carbon was considered equivalent to the dissolved organic carbon in soil samples and henceforth is referred to as DOC. The extraction method was provided by Ding et al. (2020). Briefly, soil samples (soil: water $=3: 5)$ were shaken $\left(24 \mathrm{~h}\right.$ at $\left.25^{\circ} \mathrm{C}\right)$, centrifuged (4000 r, $30 \mathrm{~min})$ and filtered ( $0.45 \mu \mathrm{m}$ polyether sulfone filters). Filtered supernatant samples were stored at $4^{\circ} \mathrm{C}$ until analysis. A solid phase extraction was used to concentrate the DOC. In brief, the pre-acidified DOC samples $(\mathrm{pH}=2)$ were loaded into solid-phase extraction cartridges (Bond Elut $\mathrm{C} 18$, Certified, PPL, $\mathrm{SCX})$ that were pre-soaked overnight in methanol and rinsed with a solution $(\mathrm{pH}=2)$ of ultrapure water, methanol and hydrochloric acid. After the DOC samples were loaded, the cartridges were rinsed with acidified ultrapure water and dried with nitrogen gas. The methanol was used to elute the DOC extracts. An elemental auto-analyzer (Vario MAX CN, Elementar Analysensysteme $\mathrm{GmbH}$, Germany) was used to determine the concentrations of DOC and DON (dissolved organic nitrogen). A FTIR spectrometer (Nicolet 6700 , Thermo Fisher Scientific Inc., USA) and a solid state ${ }^{13} \mathrm{C}$ NMR spectrometer (Bruker Avance III HD 
400 Spectrometer, Bruker BioSpin, Germany) were used to characterize the composition of carboncontaining groups in the DOC. The detailed information of FTIR and ${ }^{13} \mathrm{C}-\mathrm{NMR}$ analyses are presented in Supplementary Appendix SI.

\subsection{Data analysis}

SPSS 21.0 software (IBM Inc., Armonk, NY, USA) was used to perform the statistical analyses of the data (mean $\pm S D, n=3$ ). One-way analysis of variance were used to determine significant differences in the carbon aliphatic and carbon aromaticity indices among fertilization treatments at $P<0.05$. The Bray Curtis distances between each treatment were calculated to investigate the general differences in the DOC composition in each fertilization treatment. Considering that repeated measurements were taken from the same plots, linear mixed-effects models were used and data were fitted by the "nlme" package in $R$ ( $R$ version 4.0.2) to test whether soil nutrient background effects impact carbon-containing groups turnover. To summarize covariations between soil physicochemical factors (e.g., basic soil properties, aggregate stability, calcium forms and magnesium forms) and the DOC composition, redundancy analysis was performed with the "vegan" package in $R$ ( $R$ version 4.0.2). Variation partitioning based on the comparison of variance explained by linear models including every possible combination of variables being proxies for soil physicochemical factors were performed. We conducted intermediary analysis in $\mathrm{R}$ ( $R$ version 4.0.2) using the "mediation" package to investigate the direct and indirect effects of fertilization practices on DOC turnover. Origin 2020 (OriginLab, Northampton, USA) was used to visualize the results.

\section{Results}

\subsection{Chemical DOC characteristics in different fertilization plots}

Among the treatments, DON concentrations were higher with the full than without the full manure application $(P$-value $=0.008)$, with the largest difference observed in the M and MNPK treatments from the other three treatments (Table S2). Concentrations of DOC was not affected by manure or chemical fertilizer applications $(P$-value $=0.456)$, and consequently the ratio of DOC and DON decreased in the plots with manure application. Across all samples taken from the 15 plots, 7 carbon-containing functional groups (N-alkyl, O-alkyl, alkyl, carbohydrate, phenolic, aryl and carbonyl) of DOC compounds were identified (Fig. 1). Most of the detected functional groups were present in all plots with fertilization, but with varying relative abundances (Fig. 1 and Table S3). In comparison to CT, O-alkyl, phenolic, aryl and carbonyl abundances were significantly higher and $\mathrm{N}$-alkyl and alkyl abundances were significantly lower in the plots with manure application (Fig. 1); the difference was most significant in the MNPK plots (Table S3). Moreover, NMR spectra indicated that the relative proportions of unsaturated groups

(phenolic, aryl, and $s p^{2}$-hybridized carbons) were the highest and the amounts of saturated groups (alkyl and carbohydrate, $s p^{3}$-hybridized carbon) were the lowest in the MNPK plots (Fig. 1b). The relative 
proportions of carbonyl carbon and O-alkyl carbon were similar among fertilization plots and were significantly greater than that of CT (Fig. 1b).

\subsection{Fertilization effects on DOC composition}

The carbon aliphatic index number of the $\mathrm{M}$ treatment was lower and carbon aromaticity index number of the $M$ treatment was higher than their respective index numbers of $C T$, reflecting the decline in amount of aliphatic carbon and rise in amount of aromatic carbon in M (Fig. 2). The chemical fertilizer application did not change the indices of aliphatic and aromatic carbon compared to those of CT (Fig. 2). The effects of fertilization practices on the DOC properties occurred via the changes in basic soil properties, aggregate stability and the chemical forms of calcium and magnesium. The labile carbon groups (i.e. Nalkyl carbon, alkyl carbon and carbohydrate carbon) were positively associated with total phosphorus, total potassium, available forms of calcium (free and exchangeable calcium), the stable form of magnesium (residual magnesium), and the stable carbon groups (i.e., phenolic, aryl and carbonyl carbon). The same carbon groups were also positively associated with available nutrients (available nitrogen, phosphorus and potassium), cation exchange capacity, soil organic carbon, available forms of magnesium (free and exchangeable magnesium), and the stable form of calcium (residual calcium, Fig. 3).

To evaluate the direct and indirect effects of fertilization practices on the DOC turnover, we analyzed the pathways of effects of fertilization practices on DOC chemical composition. Fertilization practices had direct negative effects and indirect positive effects (Fig. 4). The direct effect of fertilization practices on carbohydrate, carbonyl and $\mathrm{N}$-alkyl carbons were significantly greater than on alkyl, aryl and phenolic carbons (Fig. 4). The indirect effects of fertilization practices on DOC chemical composition were mainly reflected by the significant fertilization effects on $\mathrm{N}$-alkyl and carbohydrate carbons through soil physicochemical properties and the significant effects on alkyl carbon through calcium forms (Fig. 4). Furthermore, to estimate the relative importance of potential factors on DOC turnover, we compared the influences of soil physiochemical factors (i.e., soil physicochemical properties, calcium forms, magnesium forms and aggregate stability). Variation partitioning showed that the soil physiochemical factors accounted for $51 \%$ of the variation in composition of DOC (Fig. 5). Basic soil physicochemical properties were the most important predictor (explaining $21 \%$ of the DOC composition variation) followed by calcium forms (17\%) and magnesium forms (13\%, Fig. 5). In addition, a large part of the variation (11\%) was jointly explained by basic soil properties, calcium forms and magnesium forms. However, nearly $30 \%$ of the variation remains unexplained (Fig. 5), indicating that other agro-ecological factors contributed to the variability in DOC turnover. The unexplained variability might be related to irrigation, cultivation, crops and soil microorganisms.

\section{Discussion}

\subsection{Fertilization alters DOC chemical composition}


Although fertilization has little effect on the concentration of DOC (Table S2), it significantly affected the chemical characteristics of DOC composition. A semi-quantitative approximation of the carboncontaining groups abundances was applied and the ratios of aromatic carbon to aliphatic carbon were determined to evaluate whether DOC turnover driven by fertilization method is a result of the disappearance of the labile carbon-containing groups or of the new formations of stable carboncontaining groups (He et al. 2018; Yeasmin et al. 2017). Therefore, we scaled the relative signal intensities of FTIR and ${ }^{13} \mathrm{C}$-NMR data to the abundances of DOC groups. Those approximations indicated that the lower carbon aliphatic index value and the higher carbon aromaticity index value from $\mathrm{M}$ plots (compared to CT) were caused by the respective decreases in abundance of labile carbon-containing groups (i.e., $\mathrm{N}$-alkyl, alkyl and carbohydrate carbons) and increases in abundance of the stable carboncontaining groups (i.e. phenolic, aryl and carbonyl carbons; Figs. 1 and 2). The increase of stable carboncontaining groups promoted the enrichment of polycyclic aromatics and other highly aromatic compounds (e.g., phenol and benzoic acid), causing a reduction of DOC degradation (Li et al. 2018). Some authors reported that manure addition reduces the degradation of DOC molecules because manure decomposition produces considerable amounts of polycyclic aromatic compounds, resulting in lowmolecular-mass oxygenated polycyclic aromatic hydrocarbons (Wen et al. 2021). Although manure application increased the carbon aromaticity of DOC, the chemical fertilizer addition seemed to limit the increase (Fig. 2), suggesting the increase of aromaticity and unsaturation of DOC may be derived from microbial necrosis in addition to decomposition products or microbial residue (Crowther et al. 2015). Unexpectedly, we found that compared to CT, carbon aromaticity of DOC increased in the NPK plots, but the carbon aliphatic index was not significantly lower, indicating chemical fertilizers likely promoted the enrichment of aromatic carbon in DOC not from the turnover of aliphatic carbon in the DOC, but from the other organic carbon forms. Moreover, variation between DOC groups were the most significant in MNPK (Table S3), implying the combined application of manure and chemical fertilization accelerated the internal transformation in labile groups or stable groups, which was similar to the results reported by Wang et al. (2015). These differences of molecular composition and properties of DOC among fertilization treatments furthermore confirm the shift from low-molecular-weight to high-molecular-weight compounds was easily disturbed by agricultural management practices (Seifert et al. 2016). Furthermore, our evidence verifies the disturbance effects mainly concentrated on alkanes and aromaticity (Table S4), which may be explained by the facts that alkanes are the carbon sources of microbial propagation and aromaticity is the product of microbial metabolites (Wang et al. 2020).

\subsection{Mediation of effects of soil physiochemical factors on DOC turnover}

The likely primary mechanisms of DOC turnover are molecular self-assembly and microbial transformation (Roth et al. 2019). Low-weight molecular compounds are assembled into medium- and high-weight molecular compounds to promote DOC persistence (Ding et al. 2020). Microorganisms metabolically consume DOC components and produce new microbial-derived compounds via the degradation of organic matter (Bowen et al. 2009). The consumption, transformation and production processes of microorganisms change DOC composition via preferential degradation of active molecules 
with labile groups and cause the inert molecules to remain (Kalbitz et al. 2003). Both molecular assembly and microbial transformation are related to external factors (Li et al. 2018).

In our study, fertilization practices not only directly influence DOC composition, but also regulates the proportions of DOC groups via the mediation of soil physiochemical properties (Fig. 4). The pathways of fertilizer method that indirectly influenced the turnover of soil DOC components were mainly caused by adjustments in basic soil properties (e.g., soil pH, cation exchange capacity, and nutrient availability, Table S5), soil structure (e.g., aggregate stability, Table S6) and various forms of mineral ions (e.g., calcium and magnesium forms, Table S7). However, basic soil properties and mineral forms (including calcium and magnesium forms) were the primary mediators of fertilization effects on DOC turnover, while the mediation by soil aggregate was minimal (Fig. 5). This contrasts with some previous studies reporting a strong impact of soil aggregate on DOC (Chaplot and Cooper 2015; Cincotta et al. 2019; Xu et al. 2019). This discrepancy might be explained by the fact that the cohesive strengths of soil aggregate stability are from Van der Waals forces, hydrogen bonds or electrostatic attraction at atomic or molecular scales (Abiven et al. 2009). Relevant to this study are the cohesive forces of the calcium bridge, which is a much greater force than the cementing force of DOC molecules (Wuddivira and Camps 2007). Moreover, our results showed that our fertilization treatments had little influence on soil aggregate stability (Table S6), and the data also indirectly support that the strength of cohesion of aggregates in the gray desert soil likely comes from the internal calcium bonds (Jiang et al. 2017) and thus were not easily affected by external factors.

The variation in DOC composition was most strongly attributed to basic soil properties and forms of calcium and magnesium (Fig. 5), indicating that these two factors have a strong soil physiochemical imprint. Although basic soil properties and forms of calcium and magnesium explain DOC transformation well (Fig. 5), we found that the relationship between indices among basic soil properties and forms of calcium and magnesium and DOC groups differed (Fig. 3). Our results showed that the labile carbon-containing groups were positively associated with total nutrients and the stable carboncontaining groups were positively related to available nutrients. This finding supports the observation that nutrient availability is responsible for the utilization and transformation of stable groups by microorganisms (Nannipieri et al. 2017). Recent findings have demonstrated that nutrient availability fluctuates with changes in DOC characteristics in different soils (Creamer et al. 2016; Velescu et al. 2016). This highlights the regulated role of available nutrients in the soil carbon cycle, inhibiting the decomposition of organic matter in soils rich in available nutrients while promoting the decomposition of organic matter in soils lacking available nutrients (Dimassi et al. 2014). Microorganisms are the "creators" and "processors" of DOC. It has been demonstrated that the abundance of DOC molecules is significantly positively correlated with microbial diversity (Li et al. 2018). Moreover, microorganisms are also an important link connecting fertilization practice and turnover of DOC components (Hui et al. 2019). However, this study only focused on abiotic effects of soil physiochemical factors on the relationships between fertilization practice and DOC turnover. Therefore, the role that microorganisms play in DOC turnover in association with fertilization practices is an important direction for our future research. 


\section{Conclusions}

Fertilization strategies affect DOC composition. Manure application promotes the turnover of aliphatic carbon to aromatic carbon, and chemical fertilizer application inhibits this turnover. Fertilization has both direct and indirect effects on DOC turnover, and basic soil physicochemical factors are the main mediators of the indirect effects. The availability of soil nutrients and magnesium minerals enhances DOC persistence via the enrichment of stable groups in DOC composition, and the availability of calcium minerals increases DOC availability via promotion of the accumulation of labile groups in DOC composition.

\section{Declarations}

Ethics approval and consent to participate

Not applicable.

Consent for publication

Not applicable.

Availability of data and materials

The authors declare that all relevant data supporting the findings of this study are available within the article and its supplementary information files.

Competing interests

The authors declare that they have no competing interests.

Funding

This work was supported by the National Natural Science Foundation of China (grant no. 41907088) and the Science Innovation Project of the Chinese Academy of Agricultural Science (grant no. CAAS-ASTIP2016-IEDA).

Authors' contributions

Yang Zhang, Shezhe E and Yanan Wang performed the field experiment and analyzed the field data regarding the chemical composition of dissolved organic carbon. Yang Zhang was a major contributor in writing the manuscript. Nan Zhang, Cuixai Wu and Xibai Zeng reviewed and edited the manuscript. All authors read and approved the final manuscript.

\section{References}


1. Abiven S, Menasseri S, Chenu C (2009) The effects of organic inputs over time on soil aggregate stability - A literature analysis. Soil Biology \& Biochemistry 41: 1-12. https://doi.org/10.1016/j.soilbio.2008.09.015.

2. Bongiorno G, Bunemann EK, Oguejiofor CU, Meier J, Gort G, Comans R, de Goede R (2019) Sensitivity of labile carbon fractions to tillage and organic matter management and their potential as comprehensive soil quality indicators across pedoclimatic conditions in Europe. Ecological Indicators 99:38-50. https://doi.org/10.1016/j.ecolind.2018.12.008.

3. Bowen SR, Gregorich EG, Hopkins DW (2009) Biochemical properties and biodegradation of dissolved organic matter from soils. Biology and Fertility of Soils 45:733-742. https://doi.org/10.1007/s00374-009-0387-6.

4. Chaplot V, Cooper M (2015) Soil aggregate stability to predict organic carbon outputs from soils. Geoderma 243:205-213. https://doi.org/10.1016/j.geoderma.2014.12.013.

5. Chen ZM, Wang HY, Liu XW, Zhao XL, Lu DJ, Zhou JM, Li CZ (2017) Changes in soil microbial community and organic carbon fractions under short-term straw return in a rice-wheat cropping system. Soil \& Tillage Research 165:121-127. https://doi.org/10.1016/j.still.2016.07.018.

6. Cincotta MM, Perdrial JN, Shavitz A, Libenson A, Landsman-Gerjoi M, Perdrial N, Shanley JB (2019) Soil aggregates as a source of dissolved organic carbon to streams: an experimental study on the effect of solution chemistry on water extractable carbon. Frontiers in Environmental Science 7:1-14. https://doi.org/10.3389/fenvs.2019.00172.

7. Creamer CA, Jones DL, Baldock JA, Rui YC, Murphy DV, Hoyle FC, Farrell M (2016) Is the fate of glucose-derived carbon more strongly driven by nutrient availability, soil texture, or microbial biomass size? Soil Biology \& Biochemistry 103:201-212. https://doi.org/10.1016/j.soilbio.2016.08.025.

8. Crowther TW, Sokol NW, Oldfield EE, Maynard DS, Thomas SM, Bradford MA (2015) Environmental stress response limits microbial necromass contributions to soil organic carbon. Soil Biology \& Biochemistry 85:153-161. https://doi.org/10.1016/j.soilbio.2015.03.002.

9. Dimassi B, Mary B, Fontaine S, Perveen N, Revaillot S, Cohan JP (2014) Effect of nutrients availability and long-term tillage on priming effect and soil C mineralization. Soil Biology \& Biochemistry 78:332-339. https://doi.org/10.1016/j.soilbio.2014.07.016.

10. Ding Y, Shi Z, Ye Q, Liang Y, Liu M, Dang Z, Liu C (2020) Chemodiversity of Soil Dissolved Organic Matter. Environmental Science \& Technology 54:6174-6184. https://doi.org/10.1021/acs.est.0c01136.

11. Hayes MHB, Mylotte R, Swift RS (2017) Humin: its composition and importance in soil organic matter, in: Sparks, D.L. (Eds.), Advances in Agronomy, Elsevier Academic Press Inc San Diego, pp. 47138.

12. He YT, He XH, Xu MG, Zhang WJ, Yang XY, Huang SM (2018) Long-term fertilization increases soil organic carbon and alters its chemical composition in three wheat-maize cropping sites across central and south China. Soil \& Tillage Research 177:79-87. https://doi.org/10.1016/j.still.2017.11.018. 
13. Hui C, Liu B, Wei R, Jiang H, Zhao YH, Liang YC, Xu L (2019) Dynamics, biodegradability, and microbial community shift of water-extractable organic matter in rice-wheat cropping soil under different fertilization treatments. Environmental Pollution 249:686-695. https://doi.org/10.1016/j.envpol.2019.03.091.

14. Jiang MB, Wang XH, Liusui YH, Han C, Zhao CY, Liu H (2017) Variation of soil aggregation and intraaggregate carbon by long-term fertilization with aggregate formation in a grey desert soil. Catena 149:437-445. https://doi.org/10.1016/j.catena.2016.10.021.

15. Kalbitz K, Schwesig D, Schmerwitz J, Kaiser K, Haumaier L, Glaser B, Leinweber P (2003) Changes in properties of soil-derived dissolved organic matter induced by biodegradation. Soil Biology \& Biochemistry 35:1129-1142. https://doi.org/10.1016/s0038-0717(03)00165-2.

16. Leinemann T, Preusser S, Mikutta R, Kalbitz K, Cerli C, Hoschen C, Guggenberger G (2018) Multiple exchange processes on mineral surfaces control the transport of dissolved organic matter through soil profiles. Soil Biology \& Biochemistry 118:79-90. https://doi.org/10.1016/j.soilbio.2017.12.006.

17. Li HY, Wang H, Wang HT, Xin PY, Xu XH, Ma Y, Zhang ZJ (2018) The chemodiversity of paddy soil dissolved organic matter correlates with microbial community at continental scales. Microbiome 6:116. https://doi.org/10.1186/s40168-018-0561-x.

18. Li MF, Wang J, Guo D, Yang RR, Fu H (2019) Effect of land management practices on the concentration of dissolved organic matter in soil: A meta-analysis. Geoderma 344:74-81. https://doi.org/10.1016/j.geoderma.2019.03.004.

19. Li XM, Chen QL, He C, Shi Q, Chen SC, Reid BJ, Sun GX (2019) Organic carbon amendments affect the chemodiversity of soil dissolved organic matter and its associations with soil microbial communities. Environmental Science \& Technology 53:50-59.

https://doi.org/10.1021/acs.est.8b04673.

20. Li XM, Sun GX, Chen SC, Fang Z, Yuan HY, Shi Q, Zhu YG (2018) Molecular chemodiversity of dissolved organic matter in paddy soils. Environmental Science \& Technology 52:963-971. https://doi.org/10.1021/acs.est.7b00377.

21. Li Y, Nie C, Liu Y, Du W, He P (2019) Soil microbial community composition closely associates with specific enzyme activities and soil carbon chemistry in a long-term nitrogen fertilized grassland. Science of The Total Environment 654:264-274. https://doi.org/10.1016/j.scitotenv.2018.11.031.

22. Malik A, Gleixner G (2013) Importance of microbial soil organic matter processing in dissolved organic carbon production. FEMS Microbiology Ecology 86:139-148. https://doi.org/10.1111/15746941.12182.

23. Minick KJ, Fisk MC, Groffman PM (2017) Soil Ca alters processes contributing to $C$ and $N$ retention in the $\mathrm{Oa} / \mathrm{A}$ horizon of a northern hardwood forest. Biogeochemistry 132:343-357. https://doi.org/10.1007/s10533-017-0307-z.

24. Nannipieri P, Ascher J, Ceccherini MT, Landi L, Pietramellara G, Renella G (2017) Microbial diversity and soil functions. European Journal of Soil Science 68:12-26. https://doi.org/10.1111/ejss.4_12398. 
25. Roth VN, Lange M, Simon C, Hertkorn N, Bucher S, Goodall T, Gleixner G (2019) Persistence of dissolved organic matter explained by molecular changes during its passage through soil. Nature Geoscience 12:755-761. https://doi.org/10.1038/s41561-019-0417-4.

26. Said-Pullicino D, Miniotti EF, Sodano M, Bertora C, Lerda C, Chiaradia EA, Celi L (2016) Linking dissolved organic carbon cycling to organic carbon fluxes in rice paddies under different water management practices. Plant and Soil 401:273-290. https://doi.org/10.1007/s11104-015-2751-7.

27. Schmidt MWI, Torn MS, Abiven S, Dittmar T, Guggenberger G, Janssens IA, Trumbore SE (2011) Persistence of soil organic matter as an ecosystem property. Nature 478:49-56. https://doi.org/10.1038/nature10386.

28. Seifert AG, Roth VN, Dittmar T, Gleixner G, Breuer L, Houska T, Marxsen J (2016) Comparing molecular composition of dissolved organic matter in soil and stream water: Influence of land use and chemical characteristics. Science of The Total Environment 571:142-152. https://doi.org/10.1016/j.scitotenv.2016.07.033.

29. Singh S, Dutta S, Inamdar S (2014) Land application of poultry manure and its influence on spectrofluorometric characteristics of dissolved organic matter. Agriculture Ecosystems \& Environment 193:25-36. https://doi.org/10.1016/j.agee.2014.04.019.

30. Smebye A, Ailing V, Vogt RD, Gadmar TC, Mulder J, Cornelissen G, Hale SE (2016) Biochar amendment to soil changes dissolved organic matter content and composition. Chemosphere 142:100-105. https://doi.org/10.1016/j.chemosphere.2015.04.087.

31. Taylor PG, Townsend AR (2010) Stoichiometric control of organic carbon-nitrate relationships from soils to the sea. Nature 464:1178-1181. https://doi.org/10.1038/nature08985.

32. Velescu A, Valarezo C, Wilcke W (2016) Response of dissolved carbon and nitrogen concentrations to moderate nutrient additions in a tropical montane forest of south ecuador. Frontiers in Earth Science 4:1-18. https://doi.org/10.3389/feart.2016.00058.

33. Wang D, Yi W, Zhou Y, He S, Tang L, Yin X, Zhao P, Long G (2021) Intercropping and N application enhance soil dissolved organic carbon concentration with complicated chemical composition. Soil \& Tillage Research 210:104979. https://doi.org/10.1016/j.still.2021.104979.

34. Wang JJ, Liu YN, Bowden RD, Lajtha K, Simpson AJ, Huang WL, Simpson MJ (2020) Long-term nitrogen addition alters the composition of soil-derived dissolved organic matter. Acs Earth and Space Chemistry 4:189-201. https://doi.org/10.1021/acsearthspacechem.9b00262.

35. Wang P, Ma YC, Wang XH, Jiang H, Liu H, Ran W, Shen QR (2016) Spectral exploration of calcium accumulation in organic matter in gray desert soil from northwest China. Plos One 11:e0145054. https://doi.org/10.1371/journal.pone.0145054.

36. Wang YD, Hu N, Xu MG, Li ZF, Lou YL, Chen Y, Wang ZL (2015) 23-year manure and fertilizer application increases soil organic carbon sequestration of a rice-barley cropping system. Biology and Fertility of Soils 51:583-591. https://doi.org/10.1007/s00374-015-1007-2.

37. Wen YJ, Wen J, Wang Q, Bai LY, Wang YA, Su SM, Zeng XB (2021) Organic carbon preservation promoted by aromatic compound-iron complexes through manure fertilization in red soil. Journal of 
Soils and Sediments 21:295-306. https://doi.org/10.1007/s11368-020-02769-y.

38. Wen YL, Li H, Xiao J, Wang C, Shen QR, Ran W, Yu GH (2014) Insights into complexation of dissolved organic matter and $\mathrm{Al}(\mathrm{III})$ and nanominerals formation in soils under contrasting fertilizations using two-dimensional correlation spectroscopy and high resolution-transmission electron microscopy techniques. Chemosphere 111:441-449. https://doi.org/10.1016/j.chemosphere.2014.03.078.

39. Wu XQ, Wu LY, Liu Y, Zhang P, Li QH, Zhou JZ, Chakraborty R (2018) Microbial interactions with dissolved organic matter drive carbon dynamics and community succession. Frontiers in Microbiology 9:1-12. https://doi.org/10.3389/fmicb.2018.01234.

40. Wuddivira MN, Camps-Roach G (2007) Effects of organic matter and calcium on soil structural stability. European Journal of Soil Science 58:722-727. https://doi.org/10.1111/j.13652389.2006.00861.x.

41. Xu S, Chen XJ, Zhuang J (2019) Opposite influences of mineral-associated and dissolved organic matter on the transport of hydroxyapatite nanoparticles through soil and aggregates. Environmental Research 171:153-160. https://doi.org/10.1016/j.envres.2019.01.020.

42. Xu P, Zhu J, Wang H, Shi L, Zhuang Y, Fu Q, Chen J, Hu H, Huang Q (2021) Regulation of soil aggregate size under different fertilizations on dissolved organic matter, cellobiose hydrolyzing microbial community and their roles in organic matter mineralization. Science of The Total Environment 755:142595. https://doi.org/10.1016/j.scitotenv.2020.142595.

43. Yeasmin S, Singh B, Johnston CT, Sparks DL (2017) Organic carbon characteristics in density fractions of soils with contrasting mineralogies. Geochimica Et Cosmochimica Acta 218:215-236. https://doi.org/10.1016/j.gca.2017.09.007.

44. Yu GH, Wu MJ, Wei GR, Luo YH, Ran W, Wang BR, Shen QR (2012) Binding of organic ligands with $\mathrm{Al}(\mathrm{III})$ in dissolved organic matter from soil: implications for soil organic carbon storage. Environmental Science \& Technology 46:6102-6109. https://doi.org/10.1021/es3002212.

45. Yu GH, Xiao J, Hu SJ, Polizzotto ML, Zhao FJ, McGrath SP, Shen QR (2017) Mineral availability as a key regulator of soil carbon storage. Environmental Science \& Technology 51:4960-4969. https://doi.org/10.1021/acs.est.7b00305.

46. Yuan XC, Si YT, Lin WS, Yang JQ, Wang Z, Zhang QF, Yang YS (2018) Effects of short-term warming and nitrogen addition on the quantity and quality of dissolved organic matter in a subtropical Cunninghamia lanceolata plantation. Plos One 13:e0191403. https://doi.org/10.1371/journal.pone.0191403.

47. Zang HD, Blagodatskaya E, Wang JY, Xu XL, Kuzyakov Y (2017) Nitrogen fertilization increases rhizodeposit incorporation into microbial biomass and reduces soil organic matter losses. Biology and Fertility of Soils 53:419-429. https://doi.org/10.1007/s00374-017-1194-0.

48. Zhang Y, E S, Wang Y, Su S, Bai L, Wu C, Zeng X (2021) Long-term manure application enhances the stability of aggregates and aggregate-associated carbon by regulating soil physicochemical characteristics. Catena 203:105342. https://doi.org/10.1016/j.catena.2021.105342. 
49. Zhao Q, Callister SJ, Thompson AM, Kukkadapu RK, Tfaily MM, Bramer LM, Hofmockel KS (2020) Strong mineralogic control of soil organic matter composition in response to nutrient addition across diverse grassland sites. Science of The Total Environment 736:13.

https://doi.org/10.1016/j.scitotenv.2020.137839.

50. Zhu YC, Bennett JM, Marchuk A (2019) Reduction of hydraulic conductivity and loss of organic carbon in non-dispersive soils of different clay mineralogy is related to magnesium induced disaggregation. Geoderma 349:1-10. https://doi.org/10.1016/j.geoderma.2019.04.019.

\section{Figures}

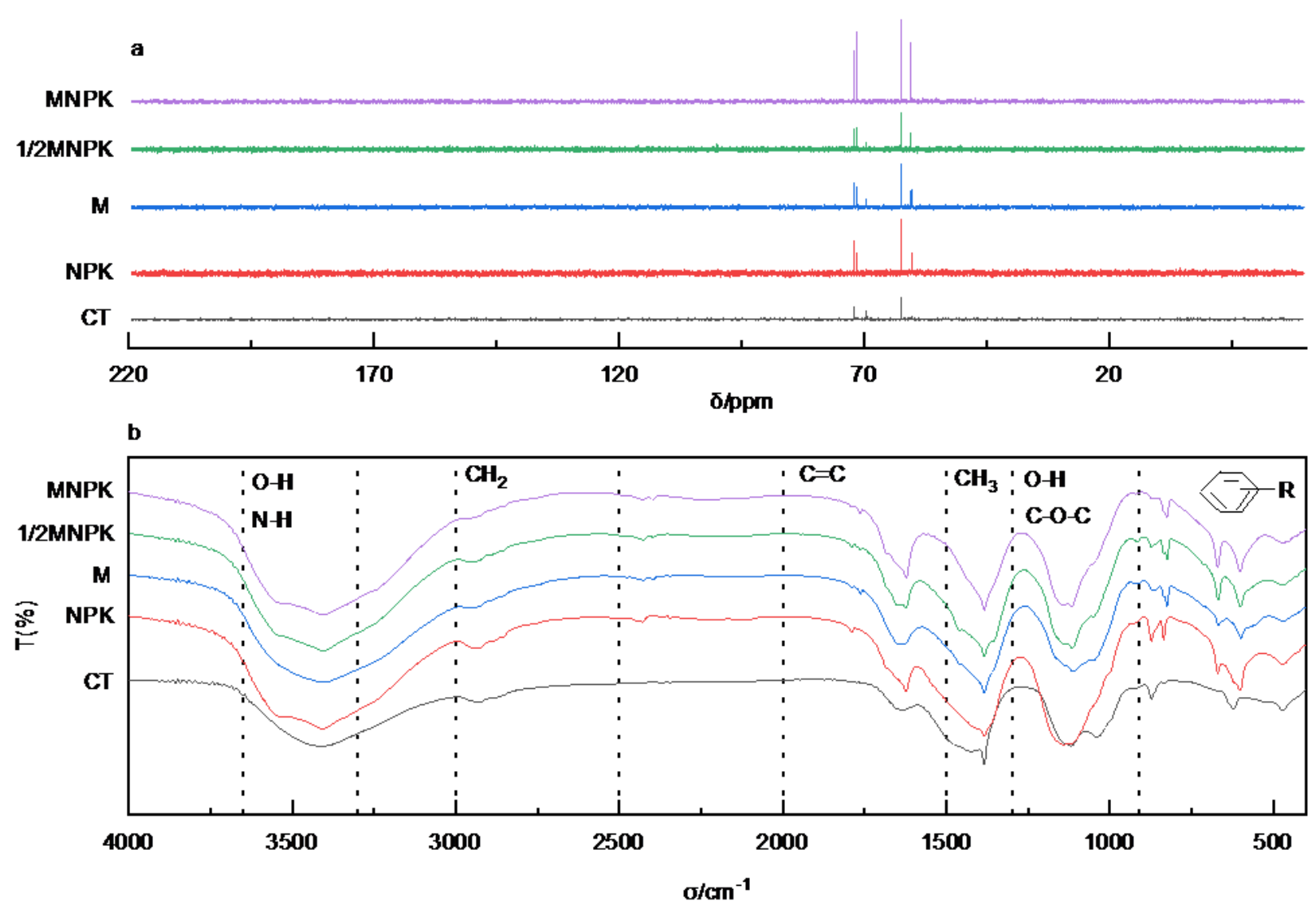

\section{Figure 1}

FTIR spectrum (a) and 13C-NMR spectrum (b) of DOC from five fertilization treatments (CT, no fertilization; NPK, chemical nitrogen, phosphorus and potassium fertilizers; $\mathrm{M}$, pig and cattle manure; 1/2MNPK, fertilization with 1/2 M and 1/2 NPK; MNPK, fertilization with total NPK and total M). 


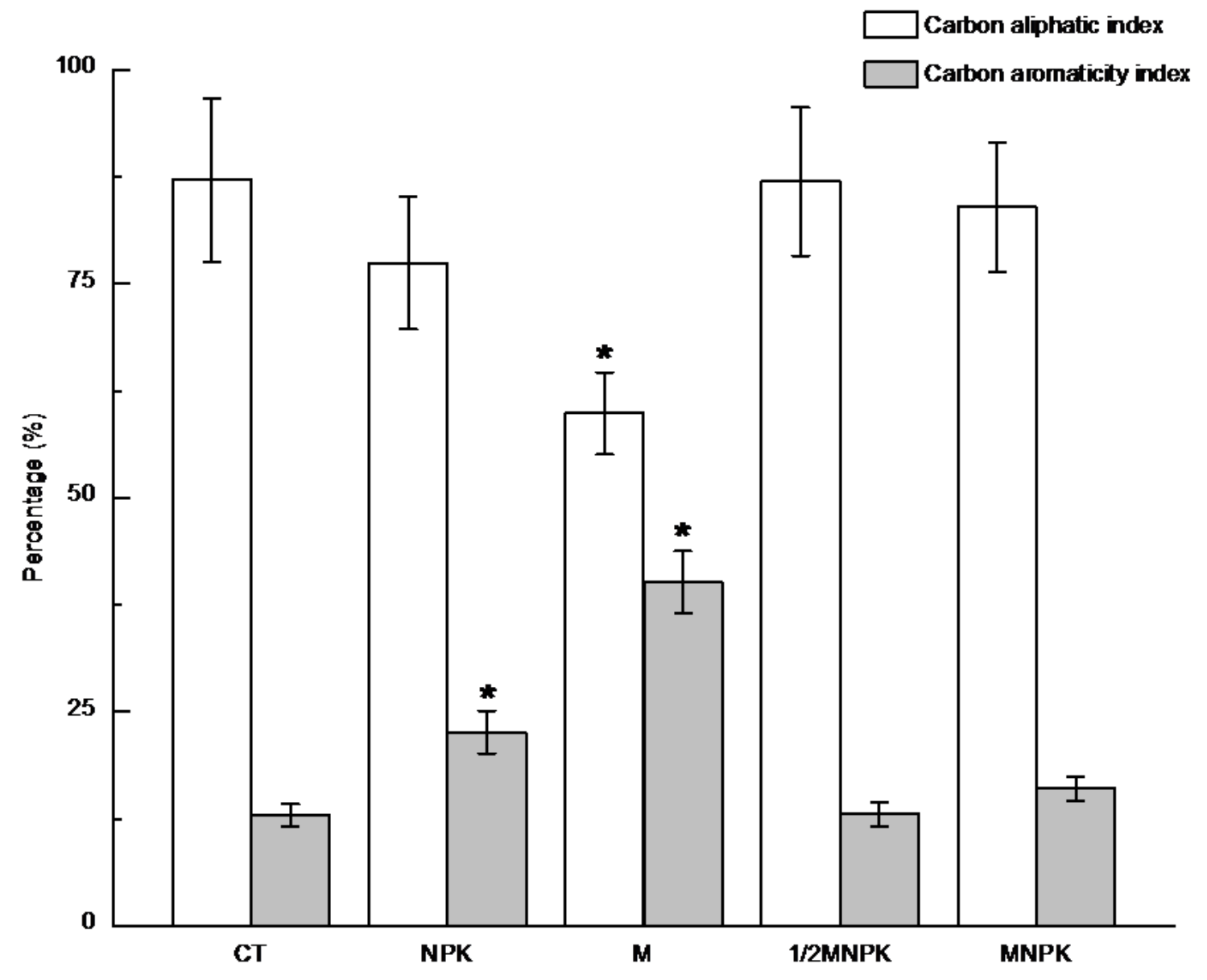

Figure 2

Carbon aliphatic and carbon aromaticity indices of DOC under influences of fertilization practices (CT, no fertilization; NPK, chemical nitrogen, phosphorus and potassium fertilizers; M, pig and cattle manure; 1/2MNPK, fertilization with $1 / 2 \mathrm{M}$ and $1 / 2$ NPK; MNPK, fertilization with total NPK and total M). * indicates a significant difference at $P<0.05$. Error bars represent $S E s$. 

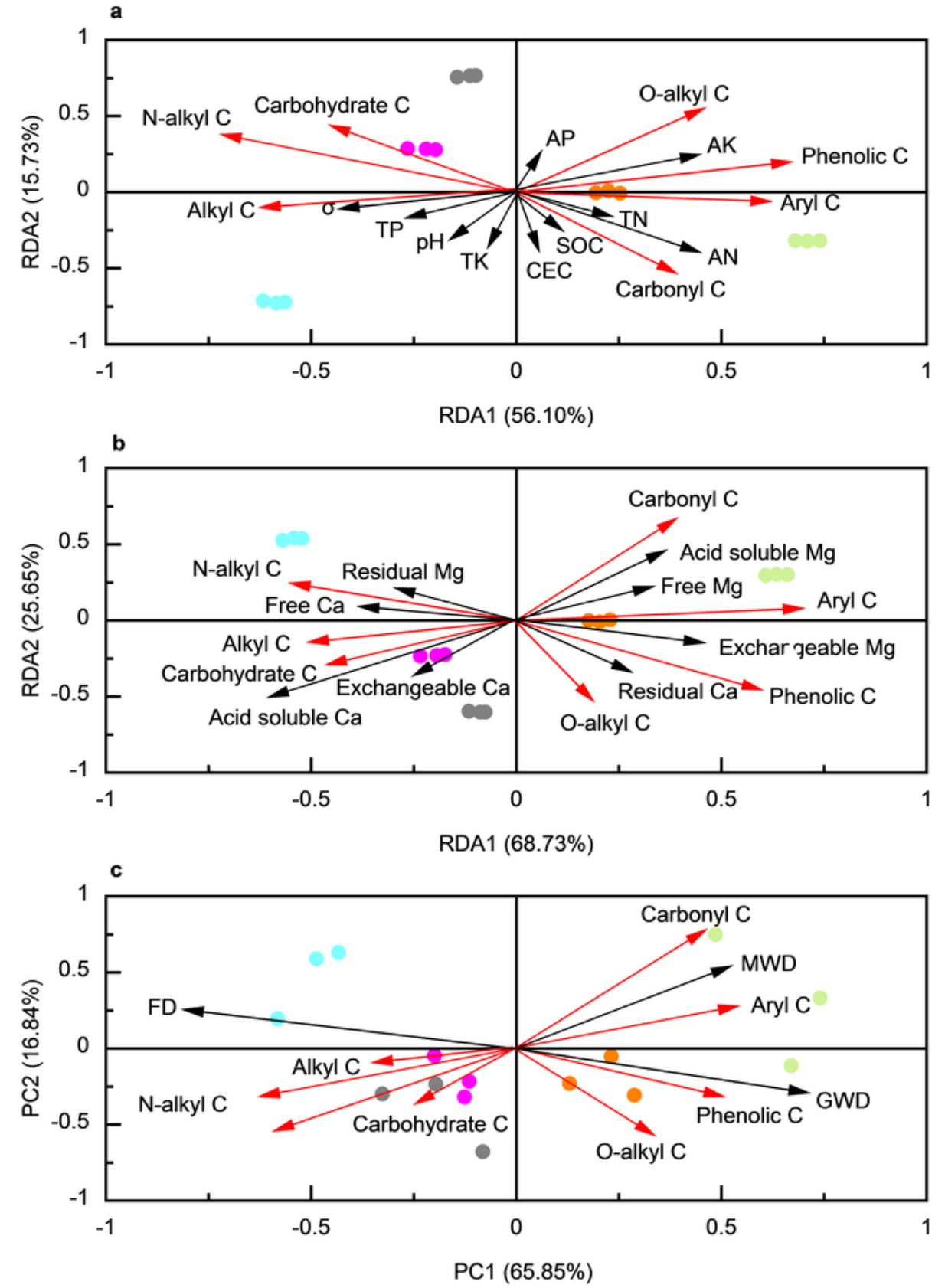

CT NPK M $\bigcirc$ M

\section{Figure 3}

Redundancy analysis of DOC composition (consisting of the N-alkyl, O-alkyl, alkyl, carbohydrate, phenolic, aryl and carbonyl $\mathrm{C}$ groups) on (a) basic soil properties ( $\mathrm{pH}$, soil acidity; $\sigma$, conductivity; CEC, cation exchange capacity; TN, total nitrogen; TP, total phosphorus; TK, total potassium; AN, available nitrogen; AP, available phosphorus; AK, available potassium; and SOC, soil organic carbon), (b) calcium and magnesium forms (Free Ca, free calcium; Free Mg, free magnesium; Exchangeable Ca, exchangeable 
calcium; Exchangeable Mg, exchangeable magnesium; Acid soluble Ca, acid-soluble calcium; Acid soluble Mg, acid-soluble magnesium; Residual $\mathrm{Ca}$, residual calcium; Residual Mg, residual magnesium) and (c) aggregate stability indices (MWD, mean weight diameter; GMD, geometric mean diameter; FD, fractal dimension) under the influence of five fertilization practices (CT, no fertilization; NPK, chemical nitrogen, phosphorus and potassium fertilizers; $M$, pig and cattle manure; $1 / 2 \mathrm{MNPK}$, fertilization with $1 / 2$ $M$ and 1/2 NPK; MNPK, fertilization with total NPK and total M).

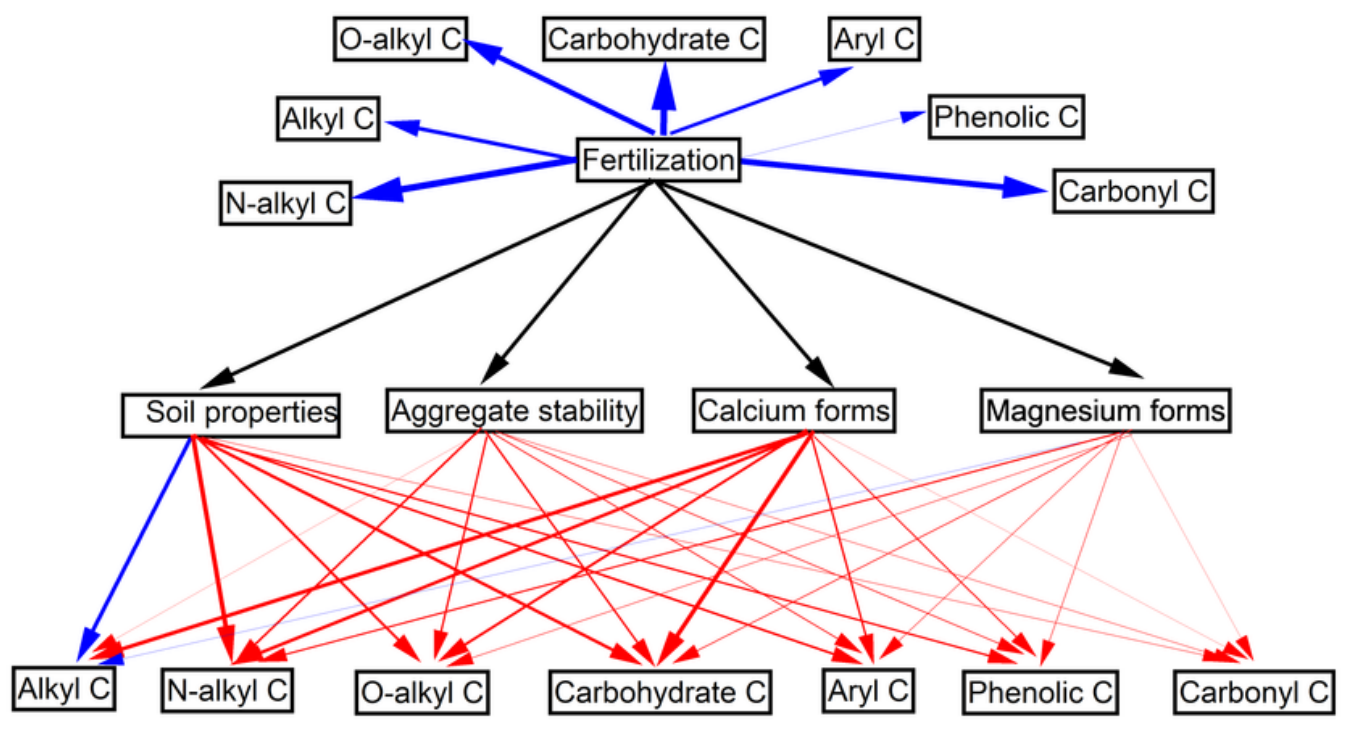

\section{Figure 4}

The direct and indirect effects (the vectors to soil properties, aggregate stability, calcium forms and magnesium forms) of fertilization treatment on DOC composition (N-alkyl C, O-alkyl C, alkyl C, carbohydrate $\mathrm{C}$, phenolic $\mathrm{C}$, aryl $\mathrm{C}$ and carbonyl $\mathrm{C}$ ). Black arrows represent indirect pathways (Path coefficient is 1). Blue arrows show negative effects and red arrows indicate positive effects; arrow thicknesses are proportional to the strengths of effects. 


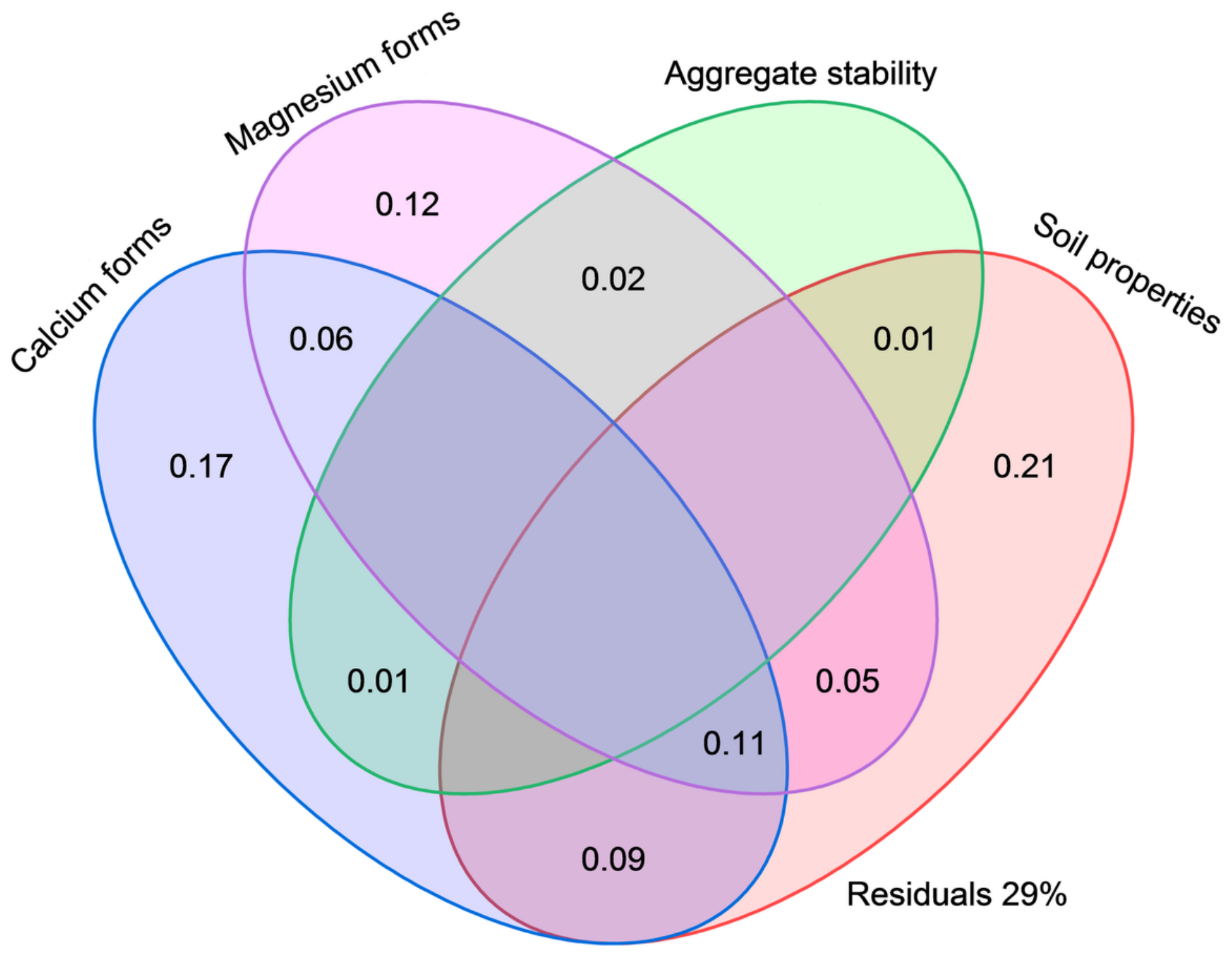

Figure 5

Variation partitioning for soil physicochemical factors (soil properties, aggregate stability, calcium forms and magnesium forms) of DOC transformation.

\section{Supplementary Files}

This is a list of supplementary files associated with this preprint. Click to download.

- Supplementarymaterial.docx 